\title{
Gene expression associated with vegetative incompatibility in Amylostereum areolatum
}

\#M.A. van der Nest ${ }^{1}$, E.T. Steenkamp ${ }^{2}$, B. Slippers ${ }^{1}$, A. Mongae ${ }^{2}$, K. van Zyl11, J. Stenlid ${ }^{3}$, M.J. Wingfield 2 and $*$ B.D. Wingfield 1

${ }^{1}$ Department of Genetics, Forestry and Agricultural Biotechnology Institute (FABI), University of Pretoria, Pretoria, 0002, South Africa; 2Department of Microbiology and Plant Pathology, Forestry and Agricultural Biotechnology Institute (FABI), University of Pretoria, Pretoria, 0002, South Africa; 3 Department of Forest Mycology and Pathology, Swedish University of Agricultural Sciences, Uppsala, 750 07, Sweden.

${ }^{*}$ Corresponding author:

E-mail: brenda.wingfield@fabi.up.ac.za

Tel: +27-12-420-3906

Fax: +27-12-420-3960

Address:

Department of Genetics

Forestry and Agricultural Biotechnology Institute (FABI)

74 Lunnon Road, Hillcrest

Pretoria

0002

South Africa

\# Present address:

Department of Forest Mycology and Pathology

Swedish University of Agricultural Sciences

Uppsala

75007

Sweden 


\begin{abstract}
In filamentous fungi, vegetative compatibility among individuals of the same species is determined by the genes encoded at the heterokaryon incompatibility (het) loci. The hyphae of genetically similar individuals that share the same allelic specificities at their het loci are able to fuse and intermingle, while different allelic specificities at the het loci result in cell death of the interacting hyphae. In this study, suppression subtractive hybridization (SSH) followed by pyrosequencing and quantitative reverse transcription PCR were used to identify genes that are selectively expressed when vegetatively incompatible individuals of Amylostereum areolatum interact. The SSH library contained genes associated with various cellular processes, including cell-cell adhesion, stress and defence responses, as well as cell death. Some of the transcripts encoded proteins that were previously implicated in the stress and defence responses associated with vegetative incompatibility. Other transcripts encoded proteins known to be associated with programmed cell death, but have not previously been linked with vegetative incompatibility. Results of this study have considerably increased our knowledge of the processes underlying vegetative incompatibility in Basidiomycetes in general and A. areolatum in particular.
\end{abstract}

Keywords: Amylostereum areolatum, Vegetative incompatibility, het loci, cell-cell adhesion, stress and defence responses, programmed cell death (PCD). 


\section{INTRODUCTION}

Programmed cell death (PCD) in eukaryotes is a genetically controlled mechanism that requires the active participation of a cell in its own death (Gilchrist, 1998). This process plays various roles in tissue development and organization. For example, PCD eliminates cells between developing digits (e.g., fingers) in animals and it is involved in leaf senescence in plants (Gilchrist, 1998). PCD is also involved in eukaryotic nonself recognition, where cell death is triggered in infected plant and animal cells to prevent the spread of the infection to surrounding tissue (Greenberg and Yao, 2004; Hückelhoven, 2007). In fungi, PCD associated with nonself recognition or "PCD by incompatibility" limits vegetative hyphal fusion between genetically different individuals (Worral, 1997; Saupe, 2000; Glass and Kaneko, 2003). Although the exact biological function of PCD associated with the nonself recognition system in fungi is not yet clear, it has recently been suggested that it may also be involved in pathogen recognition (Chevanne et al., 2010).

The nonself recognition system of filamentous fungi is controlled by genes encoded at the heterokaryon (het) or vegetative incompatibility (vic) loci (Worrall, 1997). When genetically similar individuals that share the same allelic specificities at all of their het loci meet, their hyphae fuse and their cytoplasms intermingles (Worrall, 1997). However, if the interacting individuals are genetically dissimilar with different allelic specificities at some or all of their het loci, cell death of the interacting hyphae prevents maintenance of a functional connection and a zone of inhibition is formed between the two individuals (Worrall, 1997).

At the DNA level, relatively little is known about the het loci of fungi. For the Basidiomycetes it is known only that these fungi apparently harbour fewer het loci than Ascomycetes (Worrall, 1997). The situation for the Ascomycetes is somewhat better understood, although almost all current knowledge of the het loci is based on the model species, Neurospora crassa and Podospora anserina (e.g., Kubisiak and Milgroom, 2006). However, the information obtained from these studies suggests that there is no common function among the various het genes (Saupe, 2000). In some cases, the only apparent function of certain het gene products is to control nonself recognition (e.g., het-6 in $N$. crassa and het-D and het-E loci in P. anserina), while other het gene products are also involved in additional cellular processes such as, mat in $N$. crassa and het-C in P. anserina (Saupe et al., 2000). Nevertheless, the fact that the het-E, het- 
$D$ and het- $R$ genes of $P$. anserina encode homologues with a NACHT domain (named after

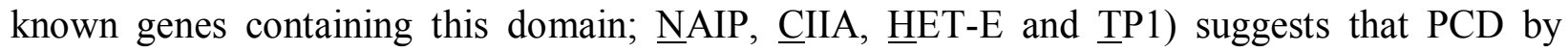
incompatibility may be related to PCD in higher eukaryotes (Paoletti et al., 2007; Pinan-Lucarré et al., 2007; Chevanne et al., 2010).

In fungi, similar mechanisms appear to underlie PCD associated with vegetative incompatibility. This is because the interactions between individuals with different allelic specificities at their het loci all share the same morphological characteristics, which include the progressive shrinkage and fragmentation of the cytoplasm resulting in the formation of discrete remnants (Bursch, 2001; Marek et al., 2003). As these remnants resemble 'apoptotic bodies', it was initially believed that PCD by incompatibility is similar to Type I PCD or apoptosis (Bursch, 2001). An alternative hypothesis is that PCD by incompatibility is similar to Type II PCD or autophagy, where cells undergoing autophagy display morphological features such as vacuolization and cell lysis (Marek et al., 2003; Pinan-Lucarré et al., 2003; Pinan-Lucarré et al., 2007). Although both types of cell death could be involved in this process, autophagy has been suggested as merely a consequence of PCD by incompatibility and that it does not represent an actual mechanism of PCD (Pinan-Lucarré et al., 2005). Thus, even though PCD associated with vegetative incompatibility represents one of the best studied forms of PCD in fungi, the exact mechanism of how cell death by incompatibility is activated remains unclear.

Various approaches have been used to study the mechanisms that regulate vegetative incompatibility. One method has been to use mutations that suppress PCD by incompatibility (Glass and Kaneko, 2003; Dementhon et al., 2004). For example, a mutation in the vib-1 (for vegetative incompatibility $b$ lock) gene of $N$. crassa partly suppresses mating-type associated cell death, as well as het-c/pin-c induced cell death (Glass and Kaneko, 2003; Dementhon et al., 2004). Another approach has been to study differentially expressed genes that are specifically up-regulated during vegetative incompatibility, which led to the discovery of the induced during incompatibilty (idi) genes in P. anserina (Bourges et al., 1998). More recently, PCR-based suppression subtractive hybridization ( $\mathrm{SSH}$ ) has been used to study the genes involved in fungalfungal interactions (Carpenter et al., 2005; Muthumeenakshi et al., 2007).

In this study, the nonself recognition system of the white rot fungus Amylostereum areolatum was considered. This fungus is an obligate symbiont of various Sirex woodwasp species 
(Slippers et al., 2003) and, like other Basidiomycetes, very little is known about the molecular genetics underlying its nonself recognition system other than that it harbours at least two het loci (van der Nest et al., 2008; 2009). Our aim was, therefore, to identify the mechanisms underlying vegetative incompatibility in $A$. areolatum. For this purpose, genes that are selectively expressed during vegetative incompatibility were identified using PCR-based SSH and 454-based pyrosequencing. Quantitative reverse transcription PCR (qRT-PCR) was employed to confirm up-regulation of selected transcripts and to compare the expression levels of these transcripts over time. Following the assignment of putative functions to the various up-regulated transcripts, the pathways and mechanisms involved in vegetative incompatibility were inferred.

\section{MATERIALS AND METHODS}

\section{Fungal cultures and pairing reactions}

The two heterokaryons of A. areolatum used in this study, CMW31512 (the result of pairing homokaryons CMW16848 12 and CMW16828 I $_{1}$ and CMW31513 (the result of pairing homokaryons CMW16848 ${ }_{41}$ and CMW16828 1 ), were previously synthesized and their vegetative compatibility groups determined based on hyphal morphology (van der Nest et al., 2008). One nucleus was common to the two heterokaryons, while the other nuclei were sib-related. Working cultures of the isolates were maintained on potato dextrose agar (PDA) $\left(24 \mathrm{gL}^{-1}\right.$ of PDA, $1 \mathrm{gL}^{-1}$ glucose, and $1 \mathrm{gL}^{-1}$ yeast extract) (Biolab, Johannesburg, South Africa). All of the isolates used in this study are also maintained at $4{ }^{\circ} \mathrm{C}$ in the culture collection (CMW) of the Forestry and Agricultural Biotechnology Institute (FABI), University of Pretoria, Pretoria, South Africa.

To allow for the identification of genes up-regulated during vegetative incompatibility in $A$. areolatum, a vegetatively incompatible interaction was compared with a "no pairing" reaction (i.e., a heterokaryon that is not interacting with itself or another heterokaryon) (Figs. 1A and 1B). By following this approach, we hoped to identify not only the pathways and processes involved in the activation of PCD by incompatibility, but also those that underlie nonself recognition. For the incompatible interaction, heterokaryons CMW31512 and CMW31513 were paired by placing a mycelial plug ( $\pm 5 \mathrm{~mm}$ diameter) of each isolate $3 \mathrm{~cm}$ apart in the middle of $9 \mathrm{~cm}$ Petri dish containing PDA. For the "no pairing" reaction, a single mycelial plug ( $\pm 5 \mathrm{~mm}$ diameter) of 
CMW31512 was placed at the centre of a $9 \mathrm{~cm}$ Petri dish containing PDA. For both the incompatible and the "no pairing" reactions, eight replicates were prepared and incubated in the dark at $25{ }^{\circ} \mathrm{C}$. Three days after the establishment of hyphal contact between CMW31512 and CMW31513, mycelium of heterokaryon CMW31512 was harvested by scraping the mycelial tissue from all eight replicate plates and it was then frozen in liquid nitrogen. To prevent crosscontamination with hyphae from heterokaryon CMW31513, mycelia were not harvested within $0.5 \mathrm{~cm}$ from the border between the interacting mycelia. At the same time, the mycelium of CMW31512 was harvested from the eight "no pairing" reactions and frozen in liquid nitrogen. A Zeiss Stereo microscope (Zeis, Germany) was used to determine when the hyphae had come into contact.

To verify the SSH results using qRT-PCR, the incompatible and the "no pairing" reactions were repeated as described above. In addition, for comparative purposes, a compatible reaction was induced by placing two mycelial plugs ( $\pm 5 \mathrm{~mm}$ diameter) of heterokaryon CMW31512 3 $\mathrm{cm}$ apart from each other on a $9 \mathrm{~cm}$ Petri dish containing PDA (Fig. 1C). At one, two and three days after hyphal contact, mycelium was harvested as described above for heterokaryon CMW31512, where the latter isolate was involved in a "no pairing", as well as the vegetatively compatible and incompatible interactions. To achieve a biological repeat for the qRT-PCRs, the mycelium from a duplicate set of interactions were also obtained.

\section{Evans blue, Giemsa and $\alpha$-naphthol staining}

To establish if PCD is associated with vegetative incompatibility in A. areolatum, Evans blue (Jacobson et al., 1998) and Giemsa (Hutchison et al., 2009) staining were employed. Evans blue penetrates only dead cells and it was used it to compare the proportion of dead compartments between compatible and incompatible interactions. Because this staining method does not allow for differentiation between necrotic and apoptotic cell death (Chen and Dickman, 2005; Hutchison et al., 2009), Giemsa staining was used to determine if nuclear degradation, a characteristic of apoptosis, occurs during vegetative incompatibility in $A$. areolatum (Hutchison et al., 2009). Becasuse it is well established that laccases are involved in fungal-fungal interactions (e.g., Iakovlev and Stenlid, 2000), the laccase activity associated with compatible and incompatible interactions was also compared using $\alpha$-naphthol staining. 
For the staining interactions, the incompatible and the "no pairing" reactions were repeated as described above. Three days after hyphal contact, segments of hyphae of the interaction or contact zone were positioned on microscope slides after which the fungal tissue was stained with Evans blue (0.05 \%; Sigma, St. Louis, MO) for 45 minutes at room temperature and washed with phosphate buffered saline (Jacobson et al., 1998). A Zeiss Axiocam light microscope using Zeis software (Zeis, Germany) was then used to determine the proportion of dead compartments. Calculations were based on the mean of 10 replicates per sample per time point. The integrity of the nuclei between compatible and incompatible interactions was also examined by placing segments of hyphae from the interaction zone on microscope slides and staining the hyphae with Giemsa stain (Sigma). Thereafter, the stained hyphae were examined using light microscopy. Laccase activity was measured one month after hyphal contact by flooding mycelium with freshly prepared $1 \%(\mathrm{wt} / \mathrm{v}) \alpha$-naphthol (Sigma) in $96 \%$ ethanol and stained for 2 hours (Iakovlev and Stenlid, 2000). Because laccase catalyses the oxidative polymerization of $\alpha$ naphthol, the extracellular activity of this enzyme was assayed visually through the appearance of the purple-coloured oxidative product.

\section{RNA isolation and cDNA preparation}

Total RNA was isolated from the frozen mycelium harvested from the incompatible and the "no pairing" reactions using TRIZOL Reagent (Invitrogen Life Technology). The quality and quantity of the RNA samples was determined using the Nanodrop ND-1000 (Nanodrop Technologies, Wilmington, DE, USA) and agarose gel electrophoresis as previously described (Sambrook et al., 1989). Total RNA $\left(\mathrm{A}_{260} / \mathrm{A}_{280}>1.8\right)$ isolated from the eight incompatible reaction plates and total RNA isolated from the eight "no pairing" reactions were combined, respectively. Messenger RNA (mRNA) was purified from the pooled total RNA using a commercially available kit [Purification of poly(A) mRNA Mini NucleoTrap ${ }^{\circledR}$, MachereyNagel] following the manufacturer's recommendations. In all cases, RNA was stored at $-80{ }^{\circ} \mathrm{C}$ to maintain its integrity. Double-stranded cDNA was synthesized from the mRNA (4.0 $\mu \mathrm{g}) \mathrm{using}$ the cDNA Synthesis System (Roche Diagnostics, Mannheim) with oligo(dT) 15 primer and following the manufacturer's recommendations. cDNA $(10 \mu \mathrm{g})$ was purified using the MinElute PCR Purification Kit (Qiagen). 


\section{Preparation and sequencing of subtractive cDNA library}

The two cDNA libraries were subjected to PCR-based SSH (Diatchenko et al., 1996) by making use of the Clonetech (Palo Alto, CA) PCR Select-Subtraction cDNA kit. In principle, SSH was used to compare the mRNA transcripts between the "no pairing" and the vegetatively incompatible reactions and to obtain genes that are selectively expressed in the vegetatively incompatible reaction. The SSH library was constructed using the cDNA from the vegetatively incompatible reaction as Tester and those from the "no pairing" reaction as Driver. For this purpose, cDNA from the Driver and the Tester was digested with RsaI to generate short, bluntended double-strand cDNA. The digested cDNA was purified using the MinElute PCR Purification Kit, and the SSH Adaptors 1 or 2 ligated to the Tester cDNA. The Adaptor 1-ligated and the Adaptor 2-ligated Tester cDNAs were then separately hybridized to an excess of Driver cDNA at $68{ }^{\circ} \mathrm{C}$ for $8 \mathrm{~h}$ after denaturation at $98{ }^{\circ} \mathrm{C}$ for $90 \mathrm{~s}$. The two hybridization samples were mixed without denaturation and hybridized at $68{ }^{\circ} \mathrm{C}$ overnight with an excess of freshly denatured Driver cDNA to eliminate redundant cDNAs common to both libraries. Redundant cDNA present in the Tester library was elimated during hybridization, because the common fraction in the Tester cDNA is removed by hybridizing to the excess Driver molecules. After diluting the resulting mixture in $200 \mu \mathrm{l}$ buffer (Clonetech), two rounds of PCR were used to selectively amplify differentially expressed cDNA. The final PCR product ( $6 \mu \mathrm{g})$ was subjected to pyrosequencing using the Roche 454 GSFLX platform at Inqaba Biotech (Pretoria, Gauteng, South Africa). A single-lane sequencing run using one section of the PicoTitrePlate ${ }^{\mathrm{TM}}$ was performed. Sample preparation and analytical processing (e.g., base calling) were performed by Inqaba Biotech (http://www.inqababiotec.co.za).

\section{Evaluation of the subtraction efficiency}

Subtraction efficiency was evaluated by comparing the relative amount of the constitutively expressed glycerol-3-phosphate dehydrogenase gene in subtracted cDNA and unsubtracted cDNA by PCR using the previously designed primers GpdF and GpdR (Neves et al., 2004). The PCR was performed using a reaction mixture containing $20 \mathrm{ng}$ DNA, $0.2 \mathrm{mM}$ of each of the four dNTPs, $1.5 \mathrm{mM} \mathrm{MgCl} 2,0.5 \mu \mathrm{M}$ of each primer and $2.5 \mathrm{U}$ FastStart Taq (Roche Diagnostics, Mannheim). Thermal cycling conditions included an initial denaturation step at $94{ }^{\circ} \mathrm{C}$ for 2 min followed by 30 cycles of denaturation at $94{ }^{\circ} \mathrm{C}$ for $30 \mathrm{~s}$, annealing at $50{ }^{\circ} \mathrm{C}$ for $30 \mathrm{~s}$, extension at 
$72{ }^{\circ} \mathrm{C}$ for $30 \mathrm{~s}$, and a final extension at $72{ }^{\circ} \mathrm{C}$ for $10 \mathrm{~min}$. DNA was separated by electrophoresis on $2 \%$ agarose $(\mathrm{wt} / \mathrm{v})$ gels (Roche Diagnostics, Mannheim), stained with ethidium bromide and visualized under ultraviolet light (Sambrook et al., 1989). Sizes of the amplicons were determined by comparison against a 100 base pair (bp) molecular weight marker (O'RangeRuler ${ }^{\mathrm{TM}} 100 \mathrm{bp}$ DNA ladder, Fermentas Life Science).

\section{Sequence assembly and the identification of expressed genes}

Individual sequence reads were aligned and assembled into contigs using Vector NTI Advance ${ }^{\mathrm{TM}}$ sequence analysis software (Invitrogen Life Technology). The basic local alignment search tool (BLAST, Altschul et al., 1990) implemented in BioEdit Version 7.0.9.0 (Hall, 1999) was used to identify and filter out sequences with similarity to known ribosomal RNA (rRNA) sequences (EU249344, AJ406498, AF506405, AF238456, AF454428) among the A. areolatum expressed sequence tags (ESTs). The remaining ESTs were annotated by web-based comparisons to the non redundant (nr) protein database of the National Center for Biotechnology Information (NCBI; http://www.ncbi.nlm.nih.gov) using translated blast searches (BLASTX) (Altschul et al., 1990). A scheme, similar to that used by Skinner et al. (2001) was applied, where ESTs were grouped as either highly significant in sequence similarity (E-value $<10^{-10}$ ), moderately significant in sequence similarity (E-value $10^{-9}$ to $10^{-4}$ ), having low sequence similarity $\left(10^{-2}\right.$ and $10^{-4}$ ) or not significant in sequence similarity (E-values above $10^{-2}$ ). ESTs with significant database matches were classified into functional categories based on Gene Ontology annotations (http://www.geneontology.org/).

\section{Validation of SSH results}

qRT-PCR was used to verify the up-regulation of the A. areolatum genes identified using SSH. In order to obtain information regarding the time course of the expression of the different ESTs, total RNA was extracted from mycelium harvested from the compatible, incompatible and the "no pairing" reactions at 1,2 and 3 days after hyphal contact. Since high quality RNA is an essential requirement for qRT-PCR (Fleige et al., 2006), the extracted RNA was evaluated as described above and subjected to DNase I treatments (Invitrogen) following the supplier's protocols. For qRT-PCR, first-strand cDNA was synthesized using the DNase I-treated total RNA and random hexamer primers (First strand cDNA synthesis kit, Fermentas Life Science). 
This cDNA and specific primer pairs (Table 1), designed with Primer3 (http://bioinfo.ebc.ee/mprimer3/), were used to perform qRT-PCR with the SYBR Green I Master dye (Roche Diagnostics). Each PCR reaction $(10 \mu \mathrm{L})$ contained SYBR Green Master Mix $(5 \mu \mathrm{L})$ (Roche Diagnostics), $0.5 \mu \mathrm{M}$ of each primer and $2 \mu \mathrm{L}$ of 1:10 diluted first strand cDNA template. PCR amplification using a 384-well LightCycler 480 (Roche Diagnostics, Basel, Switzerland) was initiated at $95^{\circ} \mathrm{C}$ for $5 \mathrm{~min}$ followed by 45 cycles of $95^{\circ} \mathrm{C}$ for $5 \mathrm{~s}, 50^{\circ} \mathrm{C}$ for $5 \mathrm{~s}$ and $72^{\circ} \mathrm{C}$ for $20 \mathrm{~s}$. After amplification, a melting curve analysis was run using the program for one cycle at $95^{\circ} \mathrm{C}$ for $30 \mathrm{~s}, 60^{\circ} \mathrm{C}$ for $30 \mathrm{~s}$, and $95^{\circ} \mathrm{C}$ with 0 -s hold in the step acquisition mode, followed by cooling at $40^{\circ} \mathrm{C}$ for $30 \mathrm{~s}$. Biological repetitions (with RNAs from 2 independent cultures) for the incompatible, compatible and the "no pairing' interactions and technical repetitions for all the reactions were performed. PCR specificity and product detection was checked post-amplification by examining the temperature-dependent melting curves of the PCR products and a no-template control to confirm that there was no background contamination. To normalize the total amount of cDNA in each reaction, a portion of the 18S rRNA gene was co-amplified using the same cycling conditions described above and primers (Table 1) designed specifically for A. areolatum.

qRT-PCR is based on the number of cycles needed for amplification-generated fluorescence to reach a specific threshold of detection or the so-called Ct value (Livak and Schnittgen, 2001; Pfaffl, 2001). The Ct value for the $18 \mathrm{~S}$ rRNA gene was used to normalize the $\mathrm{Ct}$ values for the selected targets. The delta-delta cycle threshold $(\Delta \Delta \mathrm{CT})$ method (Livak and Schnittgen, 2001) was used to compare the relative expression between the different time intervals. Because this method assumes optimal real time amplification efficiency, another method that implemented efficiency correction was also applied (Pfaffl, 2001). A standard curve was generated for each of the primer pairs by plotting $\mathrm{Ct}$ values against different template dilutions. The resulting data were analyzed for PCR efficiency correction by using LightCycler 480 Relative Quantification Software (Roche Diagnostics) that used the slope of the standard curve to calculate the real time PCR efficiency. Un-paired Student's t tests were used for statistical assessments using Microsoft Excel 2007 software. Genes were considered as differentially expressed when the p-value associated with the F-value (Fisher-Snedecor) was $<0.001$, and when the mean $\Delta \Delta \mathrm{CT}$ was $\leq-0.6$ or $\geq 0.6$ (Legrand et al., 2007). 


\section{RESULTS}

\section{Evans blue, Giemsa and a-naphthol staining}

Hyphae representing compatible heterokaryons behaved as a single confluent mycelium, while a dark pigmented demarcation line was visible between incompatible heterokaryons (Figs. 2A and 2B). The results of the $\alpha$-naphthol staining experiments (Figs. 2C and 2D) demonstrated that the spatial localization of laccase activity was different between heterokaryons involved in vegetatively compatible and incompatible interactions. Laccase activity was higher in the interaction zone of heterokaryons involved in an incompatible interaction, but low or not detectable in other parts. In contrast, laccase activity was not localized to the interaction zone of heterokaryons involved in a compatible interaction where all parts of the mycelium were homogeneously purple.

The demarcation line that was visible between incompatible heterokaryons (Figs. 2A and 2B) was also characterized by sparse mycelium. This was possibly the result of cell death as the proportion of hyphae stained with Evans blue was more than twice as high for heterokaryons involved in an incompatible interaction (56.29 \%) compared to those involved in a compatible interaction $(23.79 \%)$. The Giemsa staining (results not shown) revealed that the hyphae of individuals involved in a compatible interactions displayed compact nuclei, while the hyphae of individuals involved in incompatible interactions displayed diffuse nuclear staining.

\section{Generation and analysis of subtracted cDNAs}

In the SSH library for $A$. areolatum transcripts for the constitutively expressed gene glycerol-3phosphate dehydrogenase was not detectable. This was not the case for the unsubtracted sample, which indicated that the SSH procedure had suppressed cDNA common to the "no pairing" and vegetatively incompatible reactions. Pyrosequencing of the subtracted cDNA library generated 1.85 megabases $(\mathrm{Mb})$ of sequence information that represented 8142 individual sequence reads. A large number of these $(6051,74.3 \%)$ represented rRNA sequences, indicating that the mRNA purification was inefficient at removing rRNA. After filtering out the rRNA sequences, the remaining sequence reads (2083) could be assembled into 196 contigs (representing 1319 individual sequencing reads), while 764 represented singletons, indicating that a total of 960 ESTs were identified in this study. 
BLASTX analyses using NCBI's nr protein database showed that 545 ESTs were similar to known database entries. Of these, 418 (64 contigs and 354 singletons) were not significantly similar (E-values above 10 $0^{-2}$ ), while 127 (53 contigs and 74 singletons) were significantly similar (E-values below $10^{-2}$ ) to existing database entries (Supplementary, Table 1). ESTs that share significant similarty to known sequences were submitted to GenBank (GenBank accession numbers: HS976641- HS976754). The remaining 415 ESTs (78 contigs and 337 singletons) identified in this study did not share similarity with any known sequence encoding either a known or hypothetical proteins in the nr database.

The identified ESTs that were significantly similar to known database entries were annonated and classified into functional categories based on their Gene Ontology annotations (http://www.geneontology.org/) (Fig. 4). The category with the highest representation in terms of the number of ESTs $(19.0 \%)$ was cell death, which included ESTs that share homology with genes previously implicated in the activation of cell death associated with oxidative stress (Fig. 3; Supplementary Table 1). This was followed by the nucleic acid metabolism (14.0\%) and protein metabolism (15.0\%) categories. The category containing genes associated with the cell defence and stress response were also well represented among the ESTs (12.0\%). Other categories contained ESTs displaying significant similarity to proteins involved in transport (11.0 $\%)$, energy/carbon metabolism (10.0\%), cellular structure and organization (10.0\%), cell cycle and DNA processing (5.0\%), as well as proteins for which the function is not yet known (4.0 $\%)$. Representatives of the putative genes identified in this study that are known to be involved in hyphal fusion, the stress and defence response, as well as PCD are listed in Table 2.

\section{Confirmation of SSH by $q R T-P C R$}

qRT-PCRs on independent samples confirmed that the SSH library included transcripts that were selectively induced after the hyphae made contact (Fig. 4). This was true for all of the 11 randomly selected ESTs used in the qRT-PCR analysis. The 11 targets all showed higher expression during a vegetatively incompatible reaction than during the "no pairing" reaction.

Comparison of RNA levels associated with the selected up-regulated targets at three time points made it possible to identify three expression patterns displayed during vegetative incompatibility. The first expression pattern was represented by the profiles for a putative mannoprotein, a putative MAPK (mitogen-activated protein kinase) and a putative mannose- 
specific lectin-like protein flocculin that may be associated with hyphal fusion. For all these genes, the targets were significantly up-regulated during the incompatible reaction at all three time points. Although the putative MAPK was significantly up-regulated in both the incompatible and "no pairing" reaction, its expression profiles showed a decline in mRNA levels over the investigated time period. The second expression pattern was represented by the expression profiles for genes that may be directly (laccase and tyrosinase) or indirectly (major facilitator superfamily transporter Mfs1.1, trehalose synthase and ubiquitin) associated with the cell defence response. Generally, the expression of these putative genes increased two days after hyphal contact. They were also not significantly up-regulated at any time point in the "no pairing" reactions. The third expression pattern was represented by the expression profiles for a putative ADP/ATP carrier protein, heterotrimeric protein phosphatase $(\mathrm{P} 2 \mathrm{~A})$ and $\mathrm{NADH}$-quinine oxidoreductase that may be associated with PCD. For all three genes, an increase in mRNAlevels was observed only three days after hyphal contact. Like the "cell defence" expression pattern, none of the "cell death" targets were up-regulated at any time point in the "no pairing" reactions.

\section{DISCUSSION}

SSH in combination with pyrosequencing made it possible to identify numerous genes encoding putative proteins involved in fungal nonself recognition. Many of these putative proteins are potentially implicated in hyphal fusion, stress and defence responses, PCD, as well as in signalling pathways that possibly regulate these processes. To the best of our knowledge, this study is the first to identify genes involved in vegetative incompatibility in Basidiomycetes. For this reason, the results should provide a useful framework to identify and elucidate the molecular mechanisms underlying self/nonself recognition and the activation of PCD associated with vegetative incompatibility in $A$. areolatum and other fungi.

This study highlighted the importance of cell-cell adhesion and hyphal bridge formation during vegetative incompatibility in A. areolatum and it is similar to that observed in other fungi (Pandey et al., 2004; Muthumeenakshi et al., 2007). Various ESTs were identified that encode putative proteins involved in the generation and breakdown of cell walls and in the transport of components necessary for these processes (Glass et al., 2000; Pandey et al., 2004; 
Muthumeenakshi et al., 2007). Cell-cell adhesion and recognition in A. areolatum further appear to be lectin-mediated, because the two glycoprotein-encoding ESTs identified in this study encode a putative mucin and a mannoprotein. By functioning as lectins, these proteins are thought to facilitate cell-cell adhesion by binding to cell surface carbohydrates in fungi (Fukazawa and Kagaya, 1997; Fichtner et al., 2007; Douglas et al., 2007). The fact that transcripts for both these proteins were up-regulated during vegetative compatibility and incompatibility relative to non-interacting mycelia, supports the notion that similar molecular mechanisms underlie hyphal fusion during these interactions.

Results of this study suggest that when incompatible het alleles in A. areolatum are united in the same cytoplasm, a signalling cascade is activated that is detrimental to the cell. For example, several genes encoding putative proteins involved in the production of known cellular damaging agents were identified. These included proteins that alter cellular redox potential and $\mathrm{pH}$, as well as proteins involved in the production of reactive oxygen species (ROS) (Kültz, 2005; Syntichaki et al., 2005; Dröse and Brandt, 2008). This was also confirmed by the qRT-PCR results, where the $A$. areolatum homologue of the NADH-quinone oxidoreductase was up-regulated only during the incompatible interaction. Additionally, to deal with the stresses that accompany incompatibility, $A$. areolatum appears to activate the expression of various systems to protect itself. Several of the identified ESTs encoded putative proteins that are directly involved in the sensing of stress and in the defence response (Iakovlev and Stenlid, 2000; Kültz, 2005; Horan et al., 2006; Gucciardo et al., 2007). Proteins known to be involved in the nutrient starvation response (Schmelzle et al., 2004; Aro et al., 2005, Hewald et al., 2006) were also identified, which is comparable to that found in P. anserina (Federovo et al., 2005; Pinan-Lucarré et al., 2003, 2007). qRT-PCR analyses on A. areolatum made it possible to further show that transcripts encoding putative defence response proteins were strongly up-regulated only in the vegetatively incompatibile interactions, while the results of the laccase staining experiments showed that laccases most likely contribute to the protection of cells (Eisenman et al., 2007) during vegetatively incompatibility.

Autophagy appears to accompany vegetative incompatibility in A. areolatum and this has also been found in other fungi (e.g., Pinan-Lucarré et al., 2003). Several of the genes identified in this study encoded proteins previously linked to autophagy. These included proteins involved in 
autophagosome formation (Sato and Nakano, 2007), the fusion of autophagosomes with the vacuole (Ishihara et al., 2001), as well as proteins that regulate autophagy (Meijer and Codogno, 2004; Simonsen et al., 2004). It is thus possible that autophagy is triggered during vegetative incompatibility in A. areolatum to clear degraded DNA and proteins, damaged organelles, etc. These would have resulted from cellular stresses caused by a signalling cascade that was activated by the incompatibility of het gene interactions (Meijer and Codogno, 2004; PinanLucarré et al., 2007).

When the stress-related cellular defects associated with vegetative incompatibility in $A$. areolatum become inordinately severe to be handled by autophagy, it is probable that PCD is triggered. Several of the genes identified in this study encode putative proteins (e.g., the ubiquitin activation enzyme E1 and the ADP/ATP carrier protein) involved in the activation of apoptosis following stress (Federovo et al., 2005; Orrenius et al., 2007; Pereira et al., 2007). This is consistent with previous suggestions that oxidative stress, which has been implicated in mammalian apoptosis, may also play a role in PCD in fungi (Hutchison et al., 2009). he results of the Giemsa staining experiments suggest that the DNA of individuals involved in an incompatible interaction in $A$. areolatum was degraded, a hallmark of apoptosis also found in $P$. anserina (Hutchison et al., 2009).

Based on the SSH data generated in this study, four types of signalling pathways appear to be central to the coordination of the cellular responses during vegetatively incompatibility in $A$. areolatum. These included the MAPK, cyclic adenosine monophosphate-dependent protein kinase A (RAS/cAMP-PKA), target of rapamycin (TOR) and the ceramide stress response pathways (Schubert et al., 2006; Harispe et al., 2008; Dunlop and Tee, 2009; Levin, 2005; Morita et al., 2007). Key putative regulators and effectors of these pathways (Faix and Grosses, 2006; Harispe et al., 2008; Bastidas et al., 2009) were identified in this study. Also, the TOR (Dementhon et al., 2004; Pinan-Lucarré et al., 2006), RAS/cAMP (Loubradou and Turcq, 2000) and the ceramide stress response pathways (Fedorovo et al., 2005) have previously been linked to vegetative incompatibility. However, the exact role of these signalling pathways is not clear. Since, the TOR pathway is thought to respond to general cellular integrity (Cutler et al., 2001; Meijer and Codogno, 2004; Pinan-Lucarré et al., 2005; Pinan-Lucarré et al., 2006), it may be part of the cell's defence response during vegetative incompatibility in A. areolatum. The 
RAS/cAMP pathway that is thought to be a TOR effector pathway (Loubradou and Turcq, 2000), may, therefore, also regulate key processes during vegetative incompatibility in A. areolatum. Likewise, the ceramide stress response pathway could have a role in stress-associated ceramideinduced cell death (Oh et al., 2006) during vegetative incompatibility in this fungus.

Even though vegetative incompatibility has been suggested to involve the MAPK pathway (e.g., Leslie and Zeller, 1996; Roux and Blenis, 2004), results of this study are the first to experimentally demonstrate a link with self/nonself recognition. Our qRT-PCR results also confirmed the role of a putative MAPK in this process. MAPK transcripts were already upregulated a day after hyphal contact in both the vegetatively incompatible and compatible interactions, possibly coordinating and regulating processes involved in hyphal fusion. However, its expression was up-regulated more strongly in the incompatible interaction. This is consistent with the fact that the MAPK pathway is known to regulate related processes such as hyphal fusion and autophagy (Codogno and Meijer, 2005; Lam et al., 2006; Thaiville et al., 2008; Fleissner et al., 2009; Gough, 2010).

The overall findings of this study, together with data from previous studies enable us to propose a model for the events that may occur during a vegetatively incompatible interaction in A. areolatum (Fig. 6). In this model, hyphal fusion represents a key process associated with both vegetatively incompatible and compatible interactions. After hyphal fusion, the incompatibility interaction between het gene products activates a cascade or reactions (e.g., increased ROS production, changes in $\mathrm{pH}$ and redox potential) that increase cellular stresses (e.g., degradation of DNA, organelle damage, etc.), which then trigger a stress response. During this response, the cell initially attempts to limit the damage, for example by producing proteins involved in autophagy. Then, when the damage becomes too severe, PCD is activated. These events are probably regulated by the ceramide stress response pathway, MAPK, RAS/cAMP-PKA and TOR pathways. However, to determine and/or confirm the roles played by the differentially expressed genes during vegetative incompatibility, functional experiments will be needed. 


\section{Acknowledgments}

We thank members of the Tree Protection Co-operative Programme (TPCP), the THRIP initiative of the Department of Trade and Industry (DTI) South Africa, as well as the National Research Foundation (NRF) for financial support.

\section{REFERENCES}

Altschul, S.F., Gish, W., Miller, W., Myers, E.W., Lipman, D.J., 1990. Basic local alignment search tool. J. Mol. Biol. 215, 403-410.

Aro, N., Pakula, T., Pentilä, M., 2005. Transcriptional regulation of plant cell wall degradation by filamentous fungi. FEMS Microbiol. Rev. 29, 719-739.

Bastidas, R.J., Heitman, H., Cardenas, M.E., 2009. The protein kinase TOR1 regulates adhesin gene expression in Candida albicans. PLoS Pathogens. 5, e1000294.

Bourges, N.G., Groppi, A., Barreau, C., Clave, C., Begueret, J., 1998. Regulation of gene expression during the vegetative incompatibility reaction in Podospora anserina: Characterization of three induced genes. Genet. 150, 633-641.

Bursch, W., 2001. The autophagosomal-lysosomal compartment in programmed cell death. Cell Death Diff. 8, 569-581.

Carpenter, M.A., Stewart, A., Ridgway, H.J., 2005. Identification of novel Trichoderma hamatum genes expressed during mycoparasitism using subtractive hybridisation. FEMS Microbiol. Lett. 251, 105-112.

Chen, C., Dickman, M.B., 2005. Proline suppresses apoptosis in the fungal pathogen Colletotrichum trifolii. Proc. Natl. Acad. Sci. U.S.A. 102, 3459-3464.

Chevanne, D., Saupe, S.J., Clavé, C., Paoletti, M., 2010. WD-repeat instability and diversification of the Podospora anserina hnwd non-self recognition gene family. BMC Evol. Biol. 10, 134.

Codogno, P., Meijer, A.J., 2005. Autophagy and signaling: Their role in cell survival and cell death. Cell death and Diff. 12, 1509-1518.

Cutler, N.S., Pan, X., Heitman, J., Cardenas, M.E., 2001. The TOR signal transduction cascade controls cellular differentiation in response to nutrients. Mol. Biol. 12, 4103-4113.

Dementhon, K., Saupe, S.J., Clavé, C., 2004. Characterization of IDI-4, a bZIP transcription factor inducing autophagy and cell death in the fungus Podospora anserina. Mol. Microbiol. 53, 1625-1640.

Diatchenko, L., Lau, Y.F., Campbell, A.P., Chenchik, A., Moquadam, F., Huang, B., Lukyanov, S., Lukyanov, K., Gurskaya, N., Sverdlov, E.D., Siebert, P.D., 1996. Suppression subtractive hybridization: A method for generating differentially regulated or tissue-specific cDNA probes and libraries. Proc. Natl. Acad. Sci. U.S.A. 93, 6025-6030. 
Douglas, L.M., Li, L., Yang, Y., Dranginis, A.M., 2007. Expression and characterization of the flocculin Flo11/Muc1, a Saccharomyces cerevisiae mannoprotein with homotypic properties of adhesion. Euk. Cell. 6, 2214-2221.

Dröse, S., Brandt, U., 2008. The mechanism of mitochondrial superoxide production by the cytochrome $b c 1$ complex. J. Biol. Chem. 283, 21649-21654.

Dunlop, E.A., Tee, A.R., 2009. Mammalian target of rapamycin complex 1: Signalling inputs, substrates and feedback mechanisms. Cell. Signal. 21, 827-835.

Eisenman, H.C., Mues, M., Weber, S.E., Frases, S., Chaskes, S., Gerfen, G., Casadevall, A., 2007. Cryptococcus neoformans laccase catalysesmelanin synthesis from both D- and L-DOPA.

Faix, J., Grosses, R., 2006. Staying in shape with formins. Dev. Cell. 10, 693 - 706.

Fedorova, N.D., Badger, J.H., Robson, G.D., Wortman, J.R., Nierman, W.C., 2005. Comparative analysis of programmed cell death pathways in filamentous fungi. BMC Genomics. 6, 1-14.

Fichtner, L., Schulze, F., Braus, G.H., 2007. Differential Flo8p-dependent regulation of FLO1 and FLO11 for cell-cell and cell-substrate adherence of $S$. cerevisiae S288c. Mol. Microbiol. 66, 1276-1289.

Fleige, S., Walf, V., Huch, S., Prgomet, C., Sehm, J., Pfaffl, M.W., 2006. Comparison of relative mRNA quantification models and the impact of RNA integrity in quantitative real-time RT-PCR. Biotechnol. Lett. 28, 1601-1613.

Fleissner, A., Leeder, A.C., Roca, M.G., Read, N.D., Glass, N.L., 2009. Oscillatory recruitment of signalling proteins to cell tips promotes coordinated behavior during cell fusion. Proc. Natl. Acad. Sci. USA. 106, 19387-19392.

Fukazawa, Y., Kagaya, K., 1997. Molecular bases of adhesion of Candida albicans. J. Med. Vet. Mycol. 35, 87-99.

Gilchrist, D.G., 1998. Programmed cell death in plant diseases: The purpose and promise of cellular suicide. Annu. Rev. Phytopathol. 36, 393-414.

Glass, N.L., Jacobson, D.J., Shiu, K.T., 2000. The genetics of hyphal fusion and vegetative incompatibility in filamentous ascomycetes fungi. Annu. Rev. Genet. 34, 165-186.

Glass, N.L., Kaneko, I., 2003. Fatal attraction: Nonself-recognition and heterokaryon incompatibility in filamentous fungi. Euk. Cell. 2, 1-8.

Gough, N.R., 2009. Taking turns sending and receiving. Sci. Signal. 2, ec379.

Greenberg, J.T., Yao, N., 2004. The role and regulation of programmed cell death in plantpathogen interactions. Cell. Microbiol. 6, 201-211.

Gucciardo, S., Wisniewski, J-P., Brewin, N.J., Bornemann, S., 2007. A germin-like protein with superoxide dismutase activity in pea nodules with high protein sequence identity to a putative rhicadhesis receptor. J. Exper. Bot. 58, 1161-1171.

Hall, T.A., 1999. Bioedit: A user-friendly biological sequence alignment editor and analysis program for Windows 95/98/NT, Nuc. Acids Symp. Ser. 41, 95-98. 
Harispe, L., Portela, C., Scazzocchio, C., Pefialva, M.A., Gorfinkiel, L., 2008. Ras GTPaseactivating protein regulation of actin cytoskeleton and hyphal polarity in Aspergillus nidulans. Euk. Cell. 7, 141-153.

Hewald, S., Linne, U., Scherer, M., Marahiel, M.A., Kämper, J., Bölker, M., 2006. Identification of a gene cluster for biosynthesis of mannosylerythritol lipids in the basidiomycetous fungus Ustilago maydis. Appl. Envir. Microbiol. 72, 5469-5477.

Horan, S., Bourges, I., Meunier, B., 2006. Transcriptional response to nitrosative stress in Saccharomyces cerevisiae. Yeast. 23, 519-535.

Hückelhoven, R., 2007. Cell wall-associated mechanisms of disease resistance and susceptibility. Annu. Rev. Phytopathol. 45, 101-127.

Hutchison, E., Brown, S., Tian, C., Glass, N.L., 2009. Transcriptional profiling and functional analysis of heterokaryon incompatibility in Neurospora crassa reveals that ROS, but not metacaspases, are associated with programmed cell death. Microbiol. Papers.155, 3957-3970.

Iakovlev, A., Stenlid, J., 2000. Spatiotemporal patterns of laccase activity in interacting mycelia of wood-decaying basidiomycete fungi. Microb. Ecol. 39, 236-245.

Ishihara, N., Hamasaki, M., Yokota, S., Suzuki, K., Kamada, Y., Kihara, A., Yoshimori, T., Noda, T., Ohsumi, Y., 2001. Autophagosome requires specific early sec proteins for its formation and NSF/SNARE for vacuolar fusion. Mol. Biol. Cell. 12, 3690-3702.

Jacobson, D.J., Beurkens, K., Klomparens, K.L., 1998. Microscopic and ultrastructural examination of vegetative incompatibility in partial diploids heterozygous at het loci in Neurospora crassa. Fungal Genet. Biol. 23, 45-56.

Kubisiak, T.L., Milgroom, M.G., 2006. Markers linked to vegetative incompatibility (vic) genes and a region of height heterogeneity and reduced recombination near the mating type locus (MAT) in Cryphonectria parasitica. Fungal Genet. Biol. 43, 453-463.

Kültz, D., 2005. Molecular and evolutionary basis of the cellular stress response. Annu. Rev. Physiol. 2005. 67, 225-57.

Lam, H.-M., Chiao, Y.A., Li, M.-W., Yung, Y.-K., Ji, S., 2006. Putative nitrogen sensing systems in higher plants. J. Integrative Plant Biol. 48, 873-888.

Legrand, S., Hendriks, T., Hilbert, J-L., Quillet, M-C., 2007. Characterization of expressed sequence tags obtained by SSH during somatic embryogenesis in Cichorium intybus L. BMC Plant Biology. 7, DOI: 10.1186/1471-2229-7-27.

Leslie, J.F., Zeller, K.A., 1996. Heterokaryon incompatibility in fungi - more than just another way to die. J. Genet. 75, 415-424.

Levin, D.E., 2005. Cell wall integrity signaling in Saccharomyces cerevisiae. Microbiol. Mol. Biol. Rev. 69, 262-291.

Livak, K.J., Schmittgen, T.D., 2001. Analysis of relative gene expression data using real-time quantitative PCR and the $2^{(-\Delta \Delta \mathrm{Ct})}$ method. Methods. 25, 402-408.

Loubradou, G., Turcq, B., 2000. Vegetative incompatibility in filamentous fungi: A roundabout way of understanding the phenomenon. Res. Microbiol. 151, 239-245.

Marek, S.M., Wu, J., Glass, N.L., Gilchrist, D.G., Bostock, R.M., 2003. Nuclear DNA 
degradation during heterokaryon incompatibility in Neurospora crassa. Fungal Genet. Biol. 40, 126-137.

Meijer, A.J., Codogno, P., 2004. Regulation and role of autophagy in mammalian cells. Int. J. Biochem. Cell Biol. 36, 2445-2462.

Morissette, D.C., Dauch, A., Beech, R., Masson, L., Brousseau, R., Jabaji, S., 2008. Hare isolation of mycoparasitic-related transcripts by SSH during interaction of the mycoparasite Stachybotrys elegans with its host Rhizoctonia solani. Curr. Genet. 53, 67-80.

Morita, T., Mayanagi, T., Sobue, K., 2007. Reorganization of the actin cytoskeleton via transcriptional regulation of cytoskeletal/focal adhesion genes by myocardin-related transcription factors (MRTFs/MAL/MKLs). Exp. Cell Res. 313, 3432-3445.

Muthumeenakshi, S., Sreenivasaprasad, S., Rogers, C.W., Challen, M.P., Whipps, J.M., 2007. Analysis of cDNA transcripts from Coniothyrium minitans reveals a diverse array of genes involved in key processes during sclerotial mycoparasitism. Fungal Genet. Biol. 44, 1262-1284.

Neves, L., Lages, F., Lucas, C., 2004. New insights on glycerol transport in Saccharomyces cerevisiae. FEBS Lett. 565, 160-162.

Oh, H.L., Seok, J.Y., Kwon, C.H., Kang, S.K., Kim, Y.K., 2006. Role of MAPK in ceramideinduced cell death in primary cultured astrocytes from mouse embryonic brain. NeuroToxicology. 27, 31-38.

Orrenius, S., Gogvadze, V., Zhivotovsky, B., 2007. Mitochondrial oxidative stress: Implications for cell death. Annu. Rev. Pharmacol. Toxicol. 47, 143-183.

Pandey, A., Roca, M.G., Read, N.D., Glass, N.L., 2004. Role of a mitogen-activated protein kinase pathway during conidial germination and hyphal fusion in Neurospora crassa. Euk. Cell. 3, 348-358.

Paoletti, M., Saupe, S.J., Clavé, C., 2007. Genesis of a fungal non-self recognition repertoire. Plos One. 3: e283.

Pereira, C., Camougrand, N., Manon, S., Sousa, M.J., Córte-Real, M., 2007. ADP/ATP carrier is required for mitochondrial outer membrane permeabilization and cytochrome c release in yeast apoptosis. Mol. Microbiol. 66, 571-582.

Pfaffl, M.W., 2001. A new mathematical model for relative quantification in real time RT-PCR. Nucl. Acid R. 29, 2002-2007.

Pinan-Lucarré, B., Balguerie, A., Clavé, C., 2005. Accelerated cell death in Podospora autophagy mutants. Euk. Cell. 4, 1765-1774.

Pinan-Lucarré, B., Paoletti, M., Dementhon, K., Coulary-Salin, B., Clave, C., 2003. Autophagy is induced during cell death by incompatibility and is essential for differentiation in the filamentous fungus Podospora anserina. Mol. Microbiol. 47, 321-333.

Pinan-Lucarré, B., Iraqui I., Clave, C., 2006. Podospora anserina target of rapamycin. Curr. Genet. 50, 23-31.

Pinan-Lucarré, B., Paoletti, M., Clavé, C., 2007. Cell death by incompatibility in the fungus Podospora. Sem. Cancer Biol. 17, 101-111.

Roux, P.P., Blenis, J., 2004. ERK and p38 MAPK-activated protein kinases: A family of protein 
kinases with diverse biological functions. Microbiol. Mol. Biol. Rev. 68, 320-344.

Sambrook, J., Fritsch, E.F., Maniatis, T., 1989. Molecular cloning: A laboratory manual. 2nd ed. Cold Spring Harbor Laboratory Press, Cold Spring Harbor, NY, U.S.A.

Sato, K., Nakano, A., 2007. Mechanisms of COPII vesicle formation and protein sorting. FEBS Lett. 581, 2076-2082.

Saupe, S.J., 2000. Molecular genetics of heterokaryon incompatibility in filamentous ascomycetes. Micro. Mol. Biol Rev. 64, 489-502.

Schmelzle, T., Beck, T., Martin, D.E., Hall, M.N., 2004. Activation of the RAS/Cyclic AMP pathway suppresses a TOR deficiency in yeast. Mol. Cell. Biol. 24, 338-351.

Schubert, D., Raudaskoski, M., Knabe, N., Kothe, E., 2006. Ras GTPase-activating protein GAP1 of the homobasidiomycete Schizophyllum commune regulates hyphal growth orientation and sexual development. Euk. Cell. 5, 683-695.

Simonsen, A., Birkeland, H.C.G., Gillooly, D.J., Mizushima, N., Kuma, A., Yoshimori, T., Slagsvold, T., Brech, A., Stenmark, H., 2004. Alfy, a novel FYVE-domain-containing protein associated with protein granules and autophagic membranes. J. Cell Sci. 117, 4239-4251.

Skinner, W., Keon, J., Hargreaves, J., 2001. Gene information for fungal plant pathogens from expressed sequences. Curr. Opin. Microbiol. 4, 381-386.

Slippers, B., Coutinho, T.A., Wingfield, B.D., Wingfield, M.J., 2003. A review of the genus Amylostereum and its association with woodwasps. SA J. Sci. 99, 70-74.

Syntichaki, P., Samara, C., Tavernarakis, N., 2005. The vacuolar H+-ATPase mediates intracellular acidification required for neurodegeneration in C. elegants. Curr. Biol. 15, 12491254.

Thaiville, M.M., Pan, Y.-X., Gjymishka, A., Zhong, C., Kaufman, R.J., Kilberg, M.S., 2008. MEK signalin is required for phosphorylation of eIF2 $\alpha$ following amino acid limitation of HepG2 human hepatoma cells. J. Biol. Chem. 283, 10848-10857.

Van der Nest, M.A., Slippers, B., Stenlid, J., Wilken, P.M., Vasaitis, R., Wingfield, M.J., Wingfield, B.D., 2008. Characterization of the systems governing sexual and self-recognition in the white rot Agaricomycete Amylostereum areolatum. Curr. Genet. 53, 323-336.

Van der Nest, M.A., Slippers, B., Steenkamp, E.T., De Vos, L., Van Zyl, K., Stenlid, J., Vasaitis, R., Wingfield, M.J., Wingfield, B.D., 2009. Genetic linkage map for Amylostereum arolatum reveals an association between vegetative growth and sexual and self recognition Fungal Genet. Biol. 46, 632-641.

Worral, J.J., 1997. Somatic incompatibility in basidiomycetes. Mycol. 89, 24-36. 


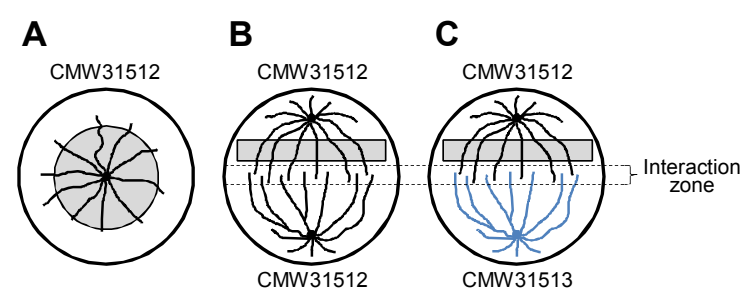

Figure 1. Mycelia for heterokaryon CMW31512 was harvested (indicated with highlighted areas) where it was (A) not involved in an interaction with any other isolate (i.e., a "no pairing" reaction), (B) where it was involved in a vegetatively compatible interaction with itself, and (C) an incompatible interaction with heterokaryon CMW31513. To prevent contamination with CMW31513 RNA, mycelia were harvested more than $0.5 \mathrm{cM}$ from the interaction zone three days after hyphal contact. The "no pairing" reaction was used as a driver, while the vegetatively incompatible reaction was used as the tester for subtractive hybridization (SSH) cDNA library construction. 

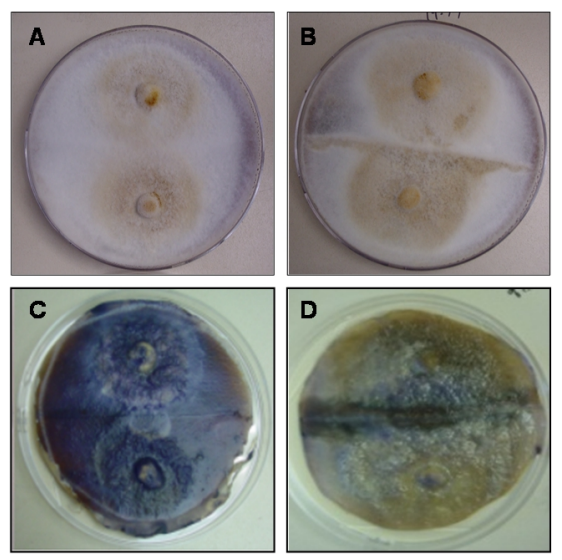

Figure 2. Macroscopic characteristics of a compatible and incompatible vegetative interaction, before and after staining with $\alpha$-naphtol. The hyphae of compatible heterokaryons behaved as one confluent mycelium (A), while a demarcation line was visible between incompatible heterokaryons (B). Compatible interactions were characterized by the non-localization of laccase activity as indicated by $\alpha$-naphtol-assays that stained entire plates purple (C). Strongly incompatible vegetative interactions were characterized by the localization of laccase activity as indicated by $\alpha$-naphtol-assays that stained only the interacting zone purple (D). 


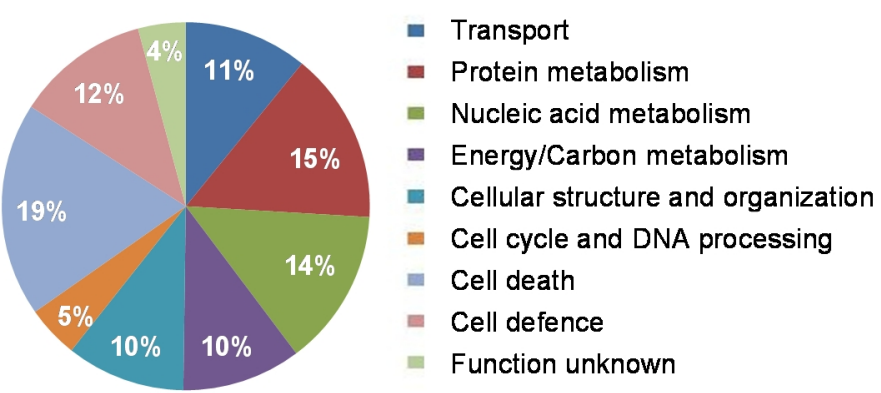

Figure 3. Distribution of the ESTs as a percentage of the total number comprising the contigs in that category. Genes were categorized in different groups according to GO annotation (http://www.geneontology.org/). 


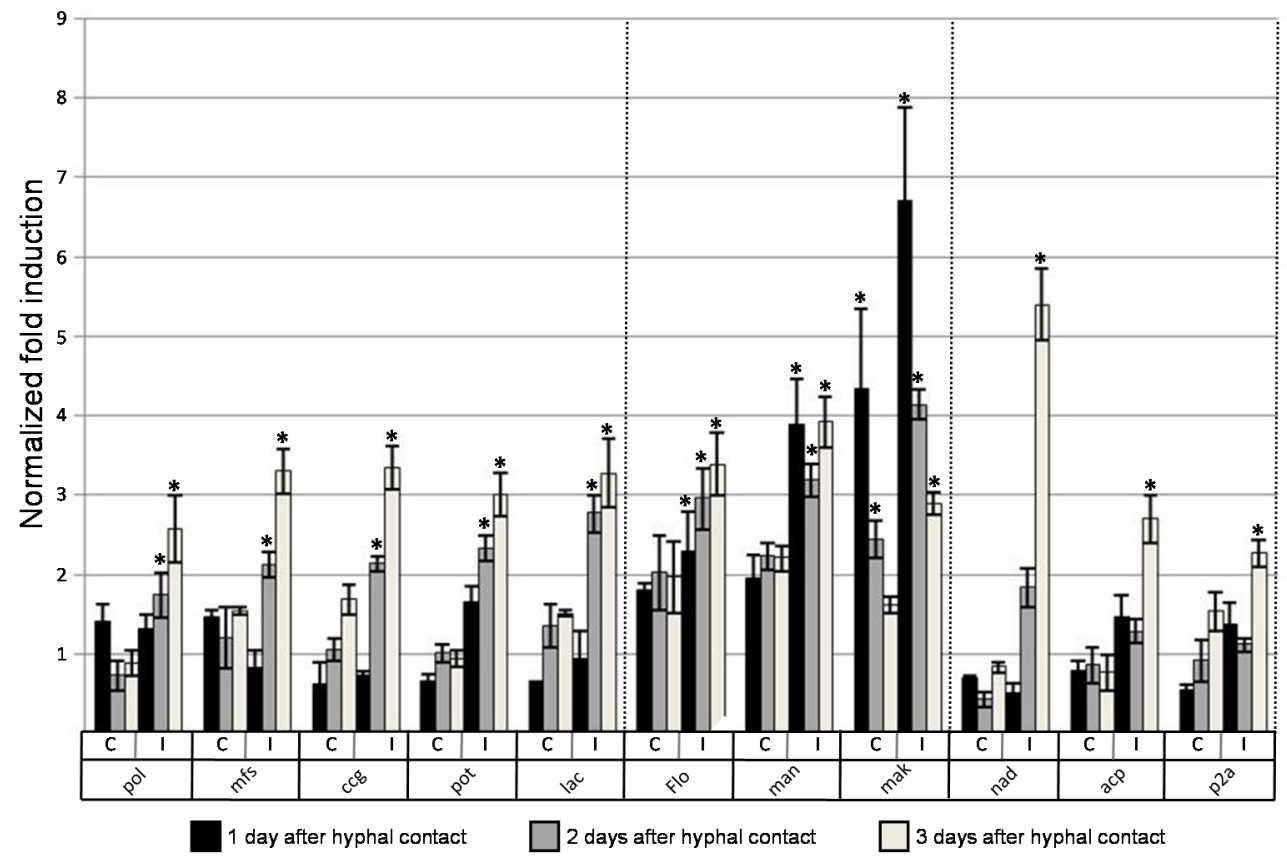

Figure 4. Comparison of gene expression during vegetative incompatibility at different time intervals. Gene expressions during vegetative incompatibility were expressed as the ratio to the average expression of the control group (no reaction) as determined using a method that implemented efficiency correction (Livak and Schnittgen, 2001). Error bars denote standard deviation (SDs) and astericks indicate significant up-regulation. Data were compared using a one-way analysis of variance. $\mathrm{C}$ indicates compatible reactions, while I indicates incompatible reactions. Pol, polyubiquitin; Mfs, Mfs1.1; Ccg, trehalose synthase (clock control gene); Pot, polyphenol oxydease (tyrosinase); Lac, laccase; Flo, flocculin; Man, mannoprotein; Mak, map kinase; NAD, NADH-quinone oxidoreductase; ACP, ADP/ATP carrier protein; P2A, heterotrimeric protein phosphatase $2 \mathrm{~A}$. Three different expression profiles were identified, based on the time the genes were up-regulated after hyphal contact (indicated with dotted lines). 
Hyphae of interacting heterokaryons fuse

Involves lectin mediated cell-cell adhesion and recognition (e.g., flocculin, mannoprotein)

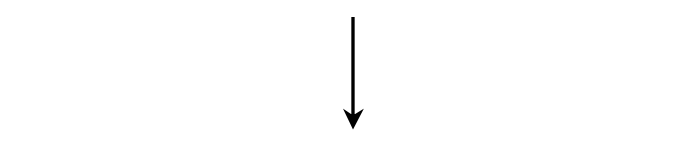

het gene products interact after hyphal fusion

If incompatible, a signalling cascade is activated that is detrimental for the cell

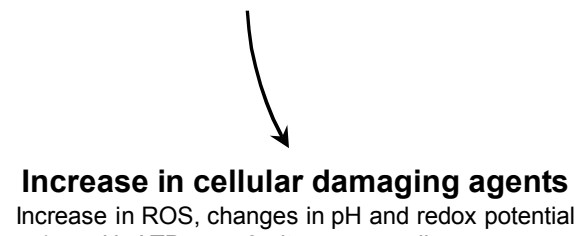

Increase in ROS, changes in $\mathrm{pH}$ and redox potential

(e.g., $\mathrm{H}^{+}$ATPases, 2-nitropropane dioxygenase, cytochrome c oxidase)
Activation of Programmed Cell Death

When the damage becomes too severe, PCD is activated (e.g., ubiquitin activation enzyme E1, AAC)

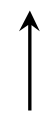

Activation of autophagy and stress response

Sensing and repairing damaged molecules, organelles, etc.

(e.g., CAT1, DNA ligase, AAD, ubiquitin, trehalose synthase)

and removing damaged molecules, organelles, etc.

(e.g., sec10 secretory, SFT2 SNARE-like proteins)

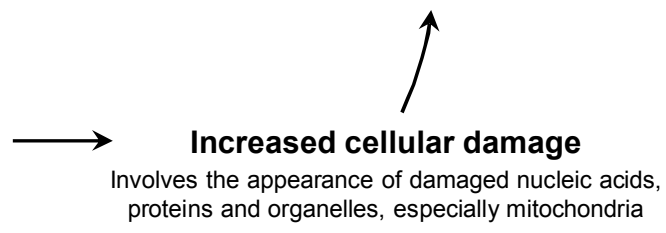

Figure 5. Proposed model for a vegetatively incompatible interaction in A. areolatum. For information regarding proteins and protein names, see Table 2 and Supplementary Table 1. 